\title{
SIGNS OF ANOMALOUS BEHAVIOR OF THE IONOSPHERE IN 2003-2014 AT F1-LAYER HEIGHTS OVER IRKUTSK
}

\author{
G.P. Kushnarenko \\ Institute of Solar-Terrestrial Physics SB RAS, \\ Irkutsk, Russia, kusch@iszf.irk.ru
}

\section{O.E. Yakovleva}

Institute of Solar-Terrestrial Physics SB RAS, Irkutsk, Russia,yakovleva@isz.j.irk.ru

\author{
G.M. Kuznetsova \\ Institute of Solar-Terrestrial Physics SB RAS, \\ Irkutsk,Russia,kuz@iszf.irk.ru
}

\begin{abstract}
We have detected an anomalous electron density $N_{\mathrm{e}}$ increase in winter months in Irkutsk in some years of the period 2003-2014. This effect was manifested when we compared the experimental values obtained by the Irkutsk ionosonde with model calculations at F1-layer heights (120-200 km). Two anomalous time zones have been found. The first was observed in the period 2003-2006 near solar minimum. In this zone, 2003 is the year of maximum manifestation of the winter $N_{\mathrm{e}}$ increase over the entire research period. The second anomalous zone - 2012, 2013, 2014 — includes
\end{abstract}

the solar maximum year, 2014. We have explored possible causes of the $N_{\mathrm{e}}$ change in winter at the F1-layer heights in all the years under study. We have found that the main factor causing the winter increase in $N_{\mathrm{e}}$ is significant geomagnetic disturbances in the above time periods.

Keywords: electron density, winter increase in $N_{\mathrm{e}}$, geomagnetic activity.

\section{INTRODUCTION}

Geomagnetic disturbances cause various changes in the complex atmosphere - ionosphere system, affecting electric fields, temperature, wind, gas composition, and all ionospheric parameters.

Under disturbed conditions, thermospheric gas composition changes extend from high latitudes to midlatitudes and then to the equator, and act on the balance of ionization processes and losses. The particular effect depends on the magnetic latitude. The gas composition in a disturbed zone exhibits a significant increase in the molecular nitrogen density and a parallel decrease in the atomic oxygen density [Buresova et al., 2002]. Satellite measurements [Goncharenko et al., 2006] indicate that the neutral composition of a disturbed zone also features a decrease in the atomic oxygen density and a significant increase in the molecular nitrogen density. These changes occur not only in summer at solar minimum, but also throughout a solar cycle during disturbed periods. SETA satellite measurements of the total neutral density near a height of $200 \mathrm{~km}$ show its increase by more than $50 \%$ at high latitudes during geomagnetic storms with a significant increase when moving equatorward [Lastovicka, 2002].

Solar ionizing radiation penetrates into all ionospheric regions, and in terms of their gas composition and various structural features we can expect a different response of each region to geomagnetic disturbances. There are numerous publications about the influence of geomagnetic storms on the ionosphere [Buresova, Lastovicka, 2001; Buresova et al., 2002; Lastovicka, 2002, 2005; Kushnarenko et al., 2018]. We, however, still lack a clear understanding of some mechanisms that determine the ionization response to geomagnetic storms, especially in the lower part of the F2 layer - at F1-layer heights. The existence of the winter anomaly, or seasonal effect, has long been known [Whitten, Poppoff, 1977; Polyakov et al., 1968; Physics of the Upper Atmosphere, 1963]. It manifests itself as a significant increase in the electron density $N_{\mathrm{e}}$ in winter months, as compared to summer, and is associated with the F2 layer. Whitten and Poppoff [1977] describe this phenomenon as follows "The winter anomaly features an increase in $N_{\mathrm{e}}$ in the F layer (mainly at middle latitudes) in December-JanuaryFebruary. The cause for this is unknown, but there is reason to believe that it is of geomagnetic origin". There are some recent works on manifestations of the winter anomaly in the total electron content during major geomagnetic disturbances, e.g., [Yasyukevich et al., 2018]. Statistical study [Ratovsky et al., 2018] shows that in winter during geomagnetic storms over Irkutsk there are the strongest positive electron density disturbances at the F2-layer peak $\left(N_{\mathrm{m}} \mathrm{F} 2\right)$; and in summer, the strongest negative disturbances of $N_{\mathrm{m}} \mathrm{F} 2$. This is indirect evidence that the winter anomaly in $N_{\mathrm{m}} \mathrm{F} 2$ increases with geomagnetic activity.

We have identified an abnormal $N_{\mathrm{e}}$ increase in winter months during some years of the period 2003-2014, when comparing the electron density array obtained from measurements made by the Irkutsk digisonde with model calculations at 120-200 km. This height range is a part of the lower ionosphere (namely the F-region), where under certain conditions the F1 layer is formed. Hereinafter, the term "F1-layer heights" will be used instead of the term "F1 layer" as the F1 layer does not exist as a separate layer in winter under undisturbed conditions at midlatitudes. However, according to observations [Buresova et al., 2002; Polekh et al., 2019], the F1 layer may occur even in winter during sufficiently strong geomagnetic storms.

We decided to study the time periods when these abnormal $N_{\mathrm{e}}$ increases at the F1-layer heights in the above years occur and to identify their causes. The purpose of this 
study is to develop knowledge about the ionospheric F1region response to geomagnetic disturbances.

\section{FORMULATION OF THE PROBLEM}

For calculations we have used the semi-empirical model (SEM), which describes the relationship of $N_{\mathrm{e}}$ with thermospheric characteristics [Shchepkin et al., 1997]. Figure 1 for the station Irkutsk shows annual variations in experimental and simulated $N_{\mathrm{e}}$ in 2003 at $12 \mathrm{LT}$ at an altitude of $200 \mathrm{~km}$, where the most pronounced daily and seasonal variations associated with solar and geomagnetic activity changes occur.

The experimental and simulated $N_{\mathrm{e}}$ values are given for the $10,20, \ldots, 360$ th days of the year. $N_{\mathrm{e}}$ measured in the winter months is 1.5-2 times higher than the simulated one. Since the simulated $N_{\mathrm{e}}$ values have been thoroughly checked by comparing with experimental data obtained at a number of mid-latitude stations [Shchepkin et al., 2005, 2007, 2008, 2009] for the different solar activity levels and seasons, there is no doubt about the correctness of the model calculations.

In our paper, we explore possible causes of the abnormal $N_{\mathrm{e}}$ increase in winter at the F1-layer heights at midlatitudes (Irkutsk) during years of different solar activity over the period 2003-2014.

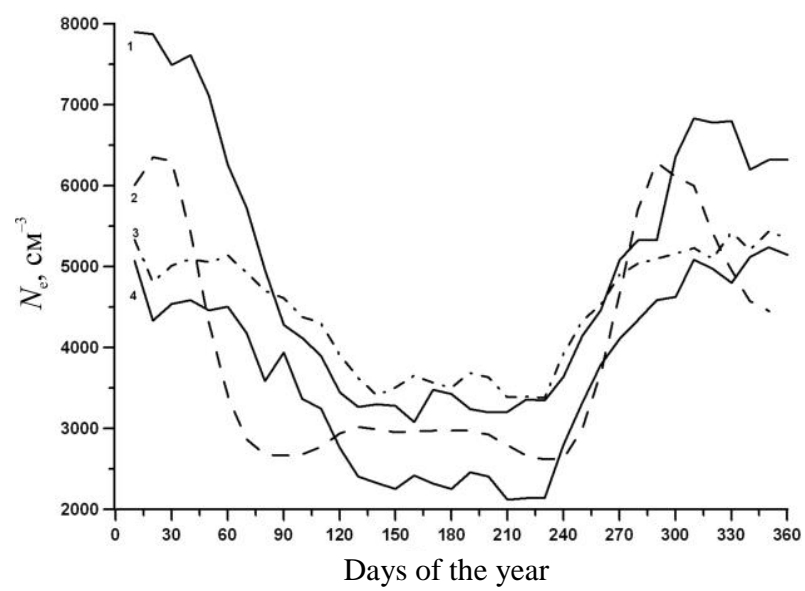

Figure 1. Experimental versus simulated $N_{\mathrm{e}}(200 \mathrm{~km}, 2003$, 12 LT): 1 - digisonde; 2 - IRI [Bilitza, 2017]; 3, 4 - SEM [Shchepkin et al., 1997] with different coefficients

\section{ATOMIC OXYGEN DENSITY VARIATION WITH HEIGHT}

The winter abnormal excess of $N_{\mathrm{e}}$ over expected values decreases as the height decreases from 200 to $120 \mathrm{~km}$. As an example, Table 1 presents experimental data on $N_{\text {ex }}$ (digisonde) for several winter days of January 2003, at 12 LT, versus the electron density calculated by SEM [Shchepkin et al., 1997] $N_{\text {clc }}$.

The nature of the altitude electron density variation indicates that one of the causes of $N_{\mathrm{e}}$ variations is likely to be an abnormal increase in the atomic oxygen content. The relative content $[\mathrm{O}]$ is of great aerodynamic importance as it determines ionospheric parameters under specific conditions [Shchepkin, Klimov, 1980]. Indeed, the relative atomic oxygen content varies with altitude in this very manner: it is very low at 120-150 $\mathrm{km}$ altitudes (10-30\% of molecular oxygen $\left[\mathrm{O}_{2}\right]$ and nitrogen $\left[\mathrm{N}_{2}\right]$ densities), but rapidly increases with height between 180 and $250 \mathrm{~km}$, being equated to the $\left[\mathrm{N}_{2}\right]$ density with a maximum at $\sim 200 \mathrm{~km}$. Specifically, the altitude variation of [O] depends greatly on heliogeophysical conditions.

\section{METHOD AND DATA}

In order to observe how the midday [O] density varies at $200 \mathrm{~km}$ in years with different solar activity levels, we have used SEM to estimate daily $k_{1}$ for $2003-2014 ; k_{1}$ is the ratio of the real atomic oxygen density, needed to match simulated $N_{\mathrm{e}}$ with experimental ones, to [O] from the working thermospheric model; $k_{1}$ is found from the SEM equation [Shchepkin et al., 2009]:

$$
\begin{aligned}
& N_{\mathrm{e}} / N_{\mathrm{av}}=X_{1}+X_{2}\left[n_{1} /\left(5 n_{2}+n_{3}\right)\right]^{1.5}+ \\
& +X_{3}\left(n_{1} / n_{3}\right)^{0.5}(\cos \chi)^{0.5}+ \\
& +X_{4} \exp \left[-\left(T_{\mathrm{ex}}-600\right) / 600\right]+X_{5}\left(E / E_{0}\right) .
\end{aligned}
$$

Here, $N_{\mathrm{av}}$ is the average value of the data on $N_{\mathrm{e}}$ separately for each height; $X_{j}$ are the coefficients of the model equation; $n_{1}, n_{2}, n_{3}$ are atomic oxygen, molecular oxygen and nitrogen densities in the thermospheric model respectively; $T_{\mathrm{ex}}$ is the exospheric temperature;

$N_{\text {ex }}$ and $N_{\text {clc }}\left(\times 10^{2}\right)$ for some days in January 2003, 12 LT, Irkutsk

\begin{tabular}{|c|c|c|c|c|c|c|c|c|}
\hline \multirow{2}{*}{$\begin{array}{c}\text { Height, } \\
\mathrm{km}\end{array}$} & \multicolumn{2}{|c|}{ January 14,2003} & \multicolumn{2}{c|}{ January 15,2003} & \multicolumn{2}{c|}{ January 16,2003} & \multicolumn{2}{c|}{ January 17, 2003 } \\
\cline { 2 - 9 } & $N_{\text {ex }}$ & $N_{\text {clc }}$ & $N_{\text {ex }}$ & $N_{\text {clc }}$ & $N_{\text {ex }}$ & $N_{\text {clc }}$ & $N_{\text {ex }}$ & $N_{\text {clc }}$ \\
\hline 120 & 7.70 & 8.60 & 7.80 & 8.60 & 7.80 & 8.60 & 7.90 & 8.70 \\
\hline 130 & 8.60 & 10.2 & 8.70 & 10.3 & 8.70 & 10.4 & 8.80 & 10.4 \\
\hline 140 & 12.7 & 11.9 & 12.7 & 12.0 & 11.0 & 12.1 & 11.5 & 12.2 \\
\hline 150 & 18.3 & 13.9 & 17.5 & 14.1 & 13.6 & 14.2 & 14.7 & 14.3 \\
\hline 160 & 26.5 & 16.7 & 24.2 & 16.8 & 17.1 & 17.1 & 18.8 & 17.2 \\
\hline 170 & 38.0 & 20.6 & 34.9 & 20.8 & 22.1 & 21.1 & 24.7 & 21.2 \\
\hline 180 & 52.3 & 25.9 & 51.3 & 26.2 & 31.0 & 26.5 & 34.2 & 26.6 \\
\hline 190 & 68.0 & 33.7 & 72.1 & 34.0 & 49.4 & 34.4 & 50.7 & 34.4 \\
\hline 200 & 84.1 & 43.2 & 94.5 & 43.5 & 75.0 & 44.0 & 74.2 & 43.9 \\
\hline
\end{tabular}


$\chi$ is the solar zenith angle; $E_{0}$ is the energy of ionizing radiation flux at solar maximum [Tobiska, Eparvier, 1998]. The working SEM calculations have been carried out using the thermospheric model NRLMSISE-00 [Picone et al., 2002]. The $N_{\mathrm{e}}$ measurements obtained by the Irkutsk digisonde were taken at 120,130,..., 190, $200 \mathrm{~km}$ for daylight hours over the period 2003-2014. Values of the F10.7 and $A_{\mathrm{p}}$ indices are adopted from the database at the WDC Kyoto [http://wdc.kugi.kyoto-u.ac.jp]. In SEM, we employed coefficients corresponding to certain years for which the $k_{1}$ values were calculated. The data can be used to estimate the desired $k_{1}$ values listed in Table 2. To make the table more compact, the $k_{1}$ values are given for two winter months (January and February) at five day intervals; for the rest of the period, at twenty day intervals. The resulting estimates of $k_{1}$ may give a clue as to whether the abnormal increases in $N_{\mathrm{ex}}$, if they exist in other years of the period considered, can, to some extent, be explained by the behavior of the relative content [O].

Let us analyze the relative density [O] variations presented in Table 2 for the years of different solar activity.

\section{$k_{1}$ in 2004-2006}

In the winter months of these years, the real [O] densities exceeded the simulated ones: in January and February $2004, k_{1}$ varied from 1.1 to 1.8. In 2005 and 2006, $k_{1}$ took values from 1.1 to 1.5 mainly in the winter months. In other seasons, $k_{1}$ varied around 1 , i.e. in accordance with the model description.

\section{imum \\ $k_{1}$ in 2003 and during the years of solar min-}

Figure 2 displays two $k_{1}$ datasets: for 2003 as anomalous geomagnetically disturbed [Panasyuk et al., 2004], and for 2009 as geomagnetically quiet. During the winter of 2003, $k_{1}$ exceeded 1, varying from 1.3 to 1.8. It is much larger than $k_{1}$ in 2009. This excess of $k_{1}$ over 1 , although to a lesser extent, is also typical for the late 2003.

It is understood that during these periods the actual atomic oxygen density exceeds the simulated one 1.5-2 times, i.e. in 2003 we should increase the [O] density in the thermospheric model in order to match the simulated $N_{\mathrm{e}}$ to those observed.

During the years of long-term minimum (20072009), geomagnetic conditions were fairly quiet. To these conditions also correspond the $k_{1}$ values: in two winter months of 2007, they are from 0.7 to 1.0. In other years of solar minimum $(2008,2009)$, its values are also close to 1 .

$k_{1}, 200 \mathrm{~km}, 12 \mathrm{LT}$, Irkutsk

\begin{tabular}{|c|c|c|c|c|c|c|c|c|c|c|c|c|}
\hline $\begin{array}{l}\text { Day } \\
\text { of the } \\
\text { year }\end{array}$ & 2003 & 2004 & 2005 & 2006 & 2007 & 2008 & 2009 & 2010 & 2011 & 2012 & 2013 & 2014 \\
\hline 1 & 1.79 & 1.25 & 1.08 & 1.45 & 0.9 & 0.82 & 0.7 & 0.76 & 1.06 & 1.29 & 1.07 & 0.96 \\
\hline 5 & 1.41 & 1.43 & 1.4 & 1.28 & 1.1 & 0.95 & 0.69 & 0.88 & 0.98 & 1.08 & 1.27 & 0.96 \\
\hline 10 & 1.98 & 1.3 & 0.94 & 1.3 & 1.03 & 0.83 & 0.76 & 0.81 & 1.19 & 1.44 & 1.3 & 1.08 \\
\hline 15 & 1.83 & 1.11 & 1.52 & 1.04 & 1.06 & 1 & 1.05 & 0.75 & 0.86 & 1.39 & 1.13 & 1.2 \\
\hline 20 & 1.36 & 1.42 & 1.28 & 1.01 & 0.71 & 0.74 & 0.9 & 0.99 & 0.89 & 1.2 & 1.44 & 1.33 \\
\hline 25 & 1.83 & 0.95 & 1.07 & 1.19 & 0.68 & 0.67 & 0.67 & 0.94 & 0.77 & 1.22 & 1.47 & 1.14 \\
\hline 30 & 1.21 & 1.07 & 1.38 & 0.94 & 1 & 0.68 & 0.7 & 1.06 & 1 & 1.36 & 1.21 & 1.27 \\
\hline 35 & 1.56 & 1.01 & 1.06 & 1.44 & 0.87 & 0.65 & 0.65 & 0.91 & 0.89 & 1.36 & 1.21 & 1.27 \\
\hline 40 & 1.61 & 1.16 & 1.01 & 1.09 & 0.94 & 1.06 & 0.67 & 0.72 & 0.87 & 1.09 & 1.22 & 1.41 \\
\hline 45 & 1.75 & 1.68 & 1.35 & 0.97 & 0.94 & 0.83 & 0.72 & 0.94 & 0.97 & 1.16 & 1.36 & 1.11 \\
\hline 50 & 1.75 & 1.45 & 1.52 & 1.38 & 1.03 & 1.11 & 1.08 & 1 & 0.98 & 1.19 & 1.15 & 1.16 \\
\hline 55 & 1.43 & 1.41 & 1.03 & 1.28 & 0.82 & 0.82 & 0.79 & 0.96 & 0.83 & 1.11 & 0.87 & 1.36 \\
\hline 60 & 1.45 & 1.19 & 1.02 & 1.09 & 1.08 & 0.69 & 0.85 & 1.09 & 0.88 & 1.45 & 1.14 & 1.04 \\
\hline 70 & 1.35 & 1.13 & 0.85 & 0.88 & 0.97 & 0.74 & 0.8 & 1.1 & 0.83 & 1.19 & 1.18 & 1.24 \\
\hline 90 & 0.92 & 1.24 & 1.23 & 0.83 & 0.74 & 1.15 & 0.86 & 0.98 & 0.94 & 1.23 & 1.23 & 1.28 \\
\hline 110 & 0.8 & 1.06 & 0.99 & 0.68 & 0.9 & 0.7 & 0.72 & 0.83 & 0.81 & 1.1 & 1.02 & 1.08 \\
\hline 130 & 0.76 & 1.01 & 0.75 & 0.93 & 0.73 & 0.56 & 0.85 & 0.83 & 0.82 & 0.86 & 0.69 & 0.86 \\
\hline 150 & 0.68 & 0.87 & 0.77 & 0.82 & 0.76 & 0.59 & 0.61 & 0.64 & 0.73 & 0.79 & 0.74 & 0.97 \\
\hline 170 & 0.82 & 0.99 & 0.62 & 0.72 & 0.81 & 0.65 & 0.69 & 0.67 & 0.69 & 0.87 & 0.79 & 0.79 \\
\hline 190 & 0.95 & 0.90 & 0.82 & 0.77 & 0.74 & 0.56 & 0.69 & 0.62 & 0.81 & 0.71 & 0.94 & 0.74 \\
\hline 210 & 0.80 & 0.85 & 0.76 & 1.08 & 0.69 & 0.67 & 0.61 & 0.61 & 0.76 & 0.72 & 0.76 & 0.80 \\
\hline 230 & 0.65 & 0.87 & 0.71 & 0.81 & 0.71 & 0.6 & 0.61 & 0.64 & 0.80 & 0.84 & 0.95 & 0.80 \\
\hline 250 & 1.05 & 0.69 & 0.69 & 0.8 & 0.64 & 0.67 & 0.91 & 0.97 & 0.90 & 0.91 & 0.79 & 0.62 \\
\hline 270 & 0.80 & 0.85 & 0.62 & 0.93 & 0.73 & 0.87 & 0.92 & 0.98 & 0.82 & 0.83 & 0.74 & 0.86 \\
\hline 290 & 1.26 & 1.09 & 1.09 & 0.96 & 0.91 & 1.0 & 1.09 & 0.86 & 1.25 & 0.97 & 1.02 & 0.93 \\
\hline 310 & 1.88 & 1.03 & 1.28 & 1.17 & 0.84 & 1.07 & 1.05 & 1.12 & 1.02 & 1.08 & 1.19 & 1.08 \\
\hline 330 & 1.52 & 1.17 & 1.07 & 1.06 & 1.25 & 0.85 & 1.42 & 0.91 & 1.0 & 1.41 & 1.15 & 0.86 \\
\hline 350 & 1.38 & 1.30 & 0.91 & 0.98 & 0.86 & 0.92 & 0.90 & 1.34 & 1.09 & 1.06 & 1.25 & 1.22 \\
\hline
\end{tabular}




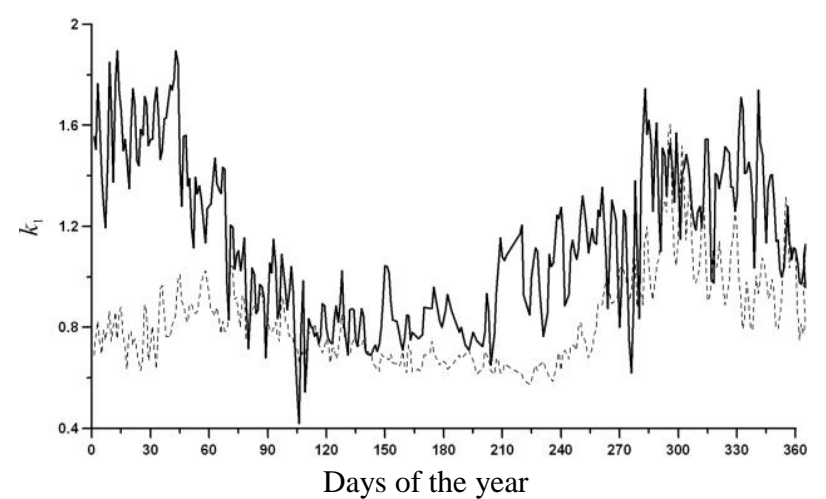

Figure 2. $k_{1}$ in 2003 (solid line) and in 2009 (dashed line), $200 \mathrm{~km}, 12 \mathrm{LT}$

Among geomagnetically quiet are 2010 and 2011 when $k_{1}$ in the winter period is $\sim 1$. Thus, the model describes well the atomic oxygen density variations under quiet conditions.

\section{$k_{1}$ in 2012-2014}

The relative content [O] in the winter months is greater than 1 and for all years varies almost equally from 1.1 to 1.5 .

\section{VARIATION IN $r=N_{\text {ex }} / N_{\text {clc }}$ IN YEARS OF DIFFERENT SOLAR ACTIVITY}

SEM has been used [Shchepkin et al., 2009] to calculate midday $N_{\text {clc }}$ at a height of $200 \mathrm{~km}$ in winter $(D=1,2, \ldots, 60)$ for the period 2003-2014. Table 3 presents the ratios $r$ of experimental electron density (digisonde) to that calculated by the model: $r=N_{\mathrm{ex}} / N_{\mathrm{clc}}$. To reduce the table size, the $r$ values are given for ten days of January, and then for every fifth day of the win- ter. Let us analyze $r$ variations during the period of interest to identify the years when there were winter increases in $N_{\text {ex }}$.

\section{$r$ in 2003-2006}

From 2003 to 2006, all $r$ values exceed 1, but the largest $r$ are observed in 2003 - from 1.3 to 2.3. In January and February 2003, there are geomagnetic disturbances with daily average $A_{\mathrm{p}}$ of 27, 32, 39, 48, 56, 67 [http://wdc.kugi.kyoto-u.ac.jp]. Significant geomagnetic events with average $A_{\mathrm{p}}$ of $37,48,58,66,84$ occurred in winter of 2004 and 2005 . The $N_{\text {ex }} / N_{\text {clc }}$ ratio during these years varied from 1.0 to 1.8 , which also confirms the $r$ dependence on the intensity of geomagnetic disturbances.

\section{$r$ in 2003 and 2007}

In the last solar cycle (peaking in 2014), the most geomagnetically disturbed year was 2003 [Panasyuk et al., 2004], and the most geomagnetically quiet period was observed during the years of solar minimum (20072009). Figure 3 for these years displays midday variations of $r$ at a height of $200 \mathrm{~km}$ in winter. $N_{\text {ex }}$ is abnormally high in January and February 2003: $r$ varies from 1.3 to 2.3; at the same time in $2007 r$ is much lower throughout the winter period.

The high $N_{\text {ex }}$ during the winter months of 2003 can be explained by UV radiation variations: in January and February 2003, the monthly average solar activity index $F 10.7$ is 139 and 121 at the annual average value of 123 . In January and February 2007, the analogous F10.7 values are 83 and 78; the annual average index, 74, i.e. $F 10.7$ is much lower than that in 2003 .

Table 3

$r=N_{\mathrm{ex}} / N_{\mathrm{clc}}$ (January and February), $200 \mathrm{~km}, 12 \mathrm{LT}$, Irkutsk

\begin{tabular}{|c|c|c|c|c|c|c|c|c|c|c|c|c|}
\hline $\begin{array}{c}\text { Day } \\
\text { of the } \\
\text { year }\end{array}$ & 2003 & 2004 & 2005 & 2006 & 2007 & 2008 & 2009 & 2010 & 2011 & 2012 & 2013 & 2014 \\
\hline 1 & 2.05 & 1.54 & 1.10 & 1.53 & 0.91 & 0.81 & 0.68 & 0.71 & 1.08 & 1.39 & 1.09 & 0.97 \\
\hline 2 & 1.40 & 1.85 & 1.76 & 1.85 & 1.26 & 0.74 & 0.67 & 0.73 & 1.05 & 1.33 & 1.16 & 1.14 \\
\hline 3 & 1.84 & 1.67 & 1.27 & 1.80 & 1.42 & 0.84 & 0.86 & 0.61 & 0.84 & 1.75 & 1.20 & 1.50 \\
\hline 4 & 2.01 & 1.28 & 1.55 & 1.35 & 1.16 & 0.76 & 0.78 & 0.97 & 1.06 & 1.44 & 1.30 & 1.02 \\
\hline 5 & 1.45 & 1.95 & 1.50 & 1.32 & 1.10 & 0.99 & 0.68 & 0.78 & 0.96 & 1.10 & 1.33 & 0.93 \\
\hline 6 & 1.40 & 1.66 & 1.00 & 1.36 & 1.04 & 0.91 & 0.69 & 0.86 & 0.93 & 1.39 & 1.49 & 1.17 \\
\hline 7 & 1.20 & 1.60 & 1.34 & 1.42 & 1.17 & 1.09 & 0.86 & 0.73 & 1.53 & 1.48 & 1.75 & 1.00 \\
\hline 8 & 1.20 & 1.50 & 0.70 & 1.09 & 1.04 & 0.82 & 0.61 & 0.81 & 1.35 & 1.64 & 1.45 & 1.47 \\
\hline 9 & 1.76 & 1.74 & 1.14 & 1.20 & 0.96 & 1.01 & 0.98 & 0.68 & 1.18 & 1.21 & 1.58 & 1.03 \\
\hline 10 & 2.05 & 1.80 & 0.94 & 1.19 & 1.03 & 0.81 & 0.75 & 0.98 & 1.26 & 1.58 & 1.30 & 1.09 \\
\hline 15 & 1.95 & 1.62 & 1.53 & 0.83 & 1.28 & 0.99 & 1.06 & 0.74 & 0.83 & 1.53 & 1.41 & 1.27 \\
\hline 20 & 1.40 & 1.45 & 1.22 & 1.34 & 0.94 & 0.72 & 0.88 & 0.90 & 0.87 & 1.25 & 1.52 & 1.45 \\
\hline 25 & 1.62 & 1.68 & 1.37 & 0.92 & 0.70 & 0.86 & 0.63 & 0.47 & 0.94 & 1.28 & 1.31 & 1.19 \\
\hline 30 & 1.26 & 1.36 & 1.47 & 1.11 & 0.98 & 0.97 & 0.69 & 0.83 & 0.84 & 1.48 & 1.41 & 1.33 \\
\hline 35 & 1.62 & 1.47 & 1.08 & 1.67 & 0.86 & 0.85 & 0.92 & 0.76 & 1.10 & 1.32 & 1.41 & 1.10 \\
\hline 40 & 1.67 & 1.32 & 1.00 & 1.01 & 0.92 & 0.79 & 0.73 & 0.96 & 0.90 & 1.06 & 1.27 & 1.33 \\
\hline 45 & 1.88 & 1.36 & 1.36 & 0.95 & 0.94 & 1.16 & 1.13 & 1.21 & 0.58 & 1.33 & 1.49 & 1.32 \\
\hline 50 & 1.87 & 1.28 & 1.57 & 1.16 & 1.02 & 1.16 & 0.84 & 0.95 & 0.99 & 1.36 & 1.19 & 1.58 \\
\hline 55 & 1.51 & 1.12 & 1.24 & 1.34 & 0.98 & 0.88 & 0.89 & 1.12 & 1.02 & 1.18 & 0.84 & 1.27 \\
\hline 60 & 1.46 & 1.12 & 1.05 & 1.11 & 1.21 & 1.16 & 0.81 & 1.25 & 0.88 & 1.11 & 1.22 & 1.26 \\
\hline
\end{tabular}




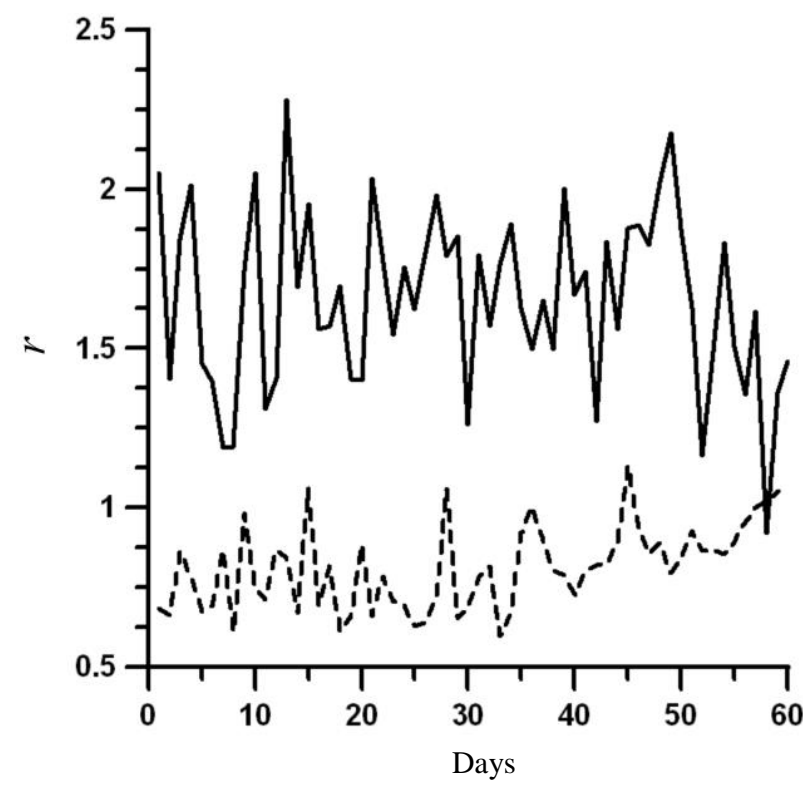

Figure 3. $r=N_{\mathrm{ex}} / N_{\mathrm{clc}}$ in 2003 (solid line) and 2007 (dashed line), $200 \mathrm{~km}, 12 \mathrm{LT}$. Along the X-axis are numbers of winter days in the year

There are other factors affecting the $N_{\mathrm{e}}$ increase such as increased values of [O] in 2003, as well as the occurrence of considerable geomagnetic disturbances in these months, as compared to 2007 . We have yet to figure out which reason ranks first in importance when analyzing the increased electron density in other years under study.

\section{$r$ in 2010 and 2011}

Basically, $r$ values are $\sim 1$, only during the first fourteen days of January $2011 r$ varies from 1.0 to 1.5 , and in 2010, $r$ is greater than 1 in the last two weeks of February. Geomagnetic disturbances occur during these periods: in the former case, with daily average $A_{\mathrm{p}}=32$, in the latter case with $A_{\mathrm{p}}=32$ and 48.

\section{$r$ in 2012-2014}

The $r$ values during all these years in winter are higher than 1 and vary from 1.0 to 1.6; in 2012 there are some increases up to 1.9 (Figure 4). We can confidently argue for the winter abnormal $N_{\mathrm{ex}}$ increase at the F1layer heights during this period.

In January 2012, $r$ is higher than in 2014, the year of solar maximum, and varies from 1.1 to 1.9. Having analyzed the $k_{1}$ variations (Table 2) for these years, we come to the conclusion that the relative content $[\mathrm{O}]$ in the winter months varied almost identically in these years - from 1.1 to 1.5 , i.e. the [O] change during this period is not crucial in explaining the $r$ increase in 2012.

As for the effect of change of solar activity, in 2012 annual average $F 10.7$ is 120 ; and monthly averages in January and February, 129 and 104. In 2014, annual average $F 10.7$ is 146 , monthly averages for January and February are 155 and 166 respectively; i.e. significantly higher than those in 2012. In this case, $r$ in 2012 in the

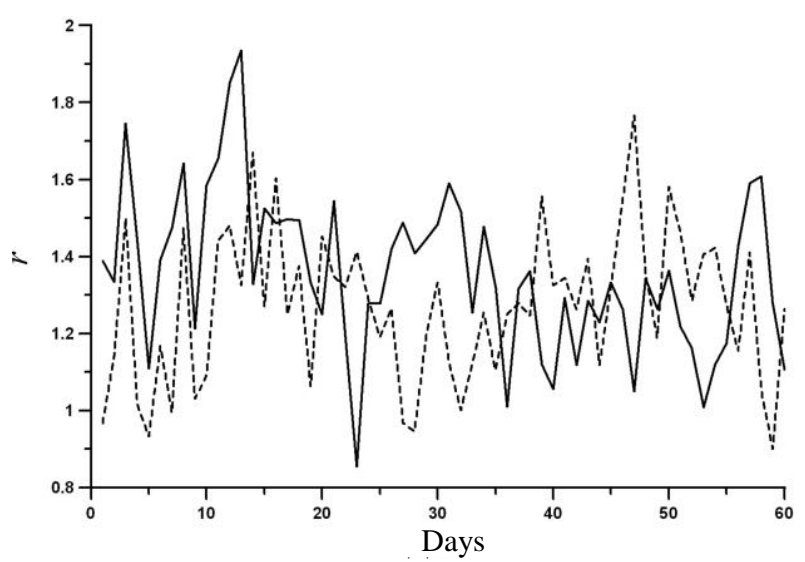

Figure 4. $r=N_{\mathrm{ex}} / N_{\mathrm{clc}}$ in 2012 (solid line) and in 2014 (dashed line), $200 \mathrm{~km}, 12 \mathrm{LT}$. Along the X-axis are numbers of winter days in the year

winter months is higher than in 2014 - the year of solar maximum, i.e. the high $F 10.7$ index is not the main factor of the $N_{\mathrm{e}}$ increase in 2012. When considering geomagnetic conditions in these years, it turns out that it is in January 2012 that the most disturbed conditions occur: their daily average $A_{\mathrm{p}}=39,56,67$, 80,154 . In 2013 and 2014, geomagnetic activity decreases. Hence, it is precisely that the geomagnetic conditions are the main cause of the high $N_{\mathrm{e}}$ values in January 2012 versus January 2014 - the year of solar maximum. The situation changes in February (Figure 4) as geomagnetic disturbances in 2014 (daily average $\left.A_{\mathrm{p}}=27,39,48,56,80,90\right)$ are more intense than those in $2012\left(A_{\mathrm{r}}=32,39,48,56\right)$. As a consequence, $r$ in February 2014 is much higher than in 2012. Thus, such a factor as intensity of geomagnetic disturbances plays the leading role in explaining the winter $N_{\mathrm{e}}$ increases at the F1-layer heights.

Consideration of the first period of the winter $N_{\mathrm{e}}$ increase (2003-2006) confirms the conclusion that in this time interval significant geomagnetic disturbances are the main factor causing the greatest $N_{\mathrm{e}}$ increases both in the winter of 2003 and throughout the period under study. Note that extreme geomagnetic events occurred in 2003 [Panasyuk et al., 2004].

Thus, we have identified two time zones of the winter $N_{\text {ex }}$ increase at F1-layer heights: the first (20032006) is near solar minimum, the second (2012-2014) includes the year of solar maximum. In the second time zone, geomagnetic disturbances have a lower intensity than those in the first. As a result, $r$ in the second time period is lower.

We consider the detected electron density increases in these time zones of the period in question as a response of the lower F-region (at F1-layer heights) to the manifestation of the winter anomaly in the upper F-region during considerable geomagnetic disturbances.

Figure 5 shows curves of $r$ (winter days) corresponding to two years with extreme geomagnetic disturbances - 2003 and 2014, and to the geomagnetically quiet year -2007 . The abnormal $N_{\mathrm{e}}$ increases manifest themselves in 2003 as the highest values of $r$ throughout the period of interest. 


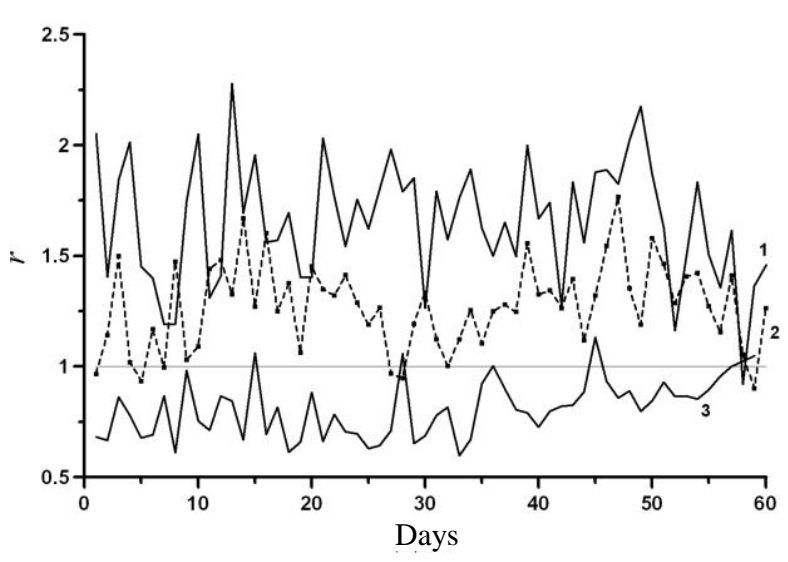

Figure 5. $r=N_{\mathrm{ex}} / N_{\mathrm{clc}}$ in 2003 (1), 2014 (2), and in 2007 (3), $200 \mathrm{~km}, 12 \mathrm{LT}$. Along the X-axis are numbers of winter days in the year

\section{CONCLUSIONS}

1. At midlatitudes (station Irkutsk) in 2003-2014, we have found two time zones of winter electron density increase at F1-layer heights: the first (2003-2006) is near solar minimum, the second (2012-2014) includes the year of solar maximum. These winter $N_{\mathrm{e}}$ increases can be thought of as a response of the lower F-region (F1-layer heights) to the manifestation of the winter anomaly in the upper part of this region during considerable geomagnetic disturbances.

2. Analysis of possible causes of the abnormal winter $N_{\mathrm{e}}$ increase in all years of the 2003-2014 period under study shows that the main factor responsible for this phenomenon at F1-layer heights is the presence of considerable geomagnetic disturbances during the winter months in the above time zones.

3. Under quiet geomagnetic conditions, working models can quite accurately describe the aerodynamic conditions at F1-layer heights.

The work was financially supported by the Ministry of Science and Higher Education of the Russian Federation (project "Study of the State and Dynamics of Earth's Atmosphere at Different Time Scales under the Influence of Geophysical, Cosmic, and Human Impacts"). The results were obtained using the equipment of Shared Equipment Center «Angara» [https://ckprf.ru/ckp/3056].

\section{REFERENCES}

Bilitza D., Altadill D., Truhlik V., Shubin V., Galkin I., Reinisch B., Huang X. International Reference Ionosphere 2016: From ionospheric climate to real-time weather predictions. Space Weather. 2017, vol. 15, pp. 418-429. DOI 10.1002/2016SW001593.

Buresova D., Lastovicka J. Changes in the F1 region electron density during geomagnetic storms at low solar activity. J. Atmos. Solar-Terr. Phys. 2001, vol. 63, pp. 537-544. DOI: 10.1016/S1364-6826(00)00167-X.

Buresova D., Lastovicka J., Altadill D., Miro G. Daytime electron density at the F1-region in Europe during geomagnetic storms. Ann. Geophys. 2002, vol. 20, pp. 1007-1021. DOI: 10.5194/angeo-20-1007-2002.

Goncharenko L. Salah J. Crowley G., Paxton L.J., Zhang Y., Coster A., Rideout W., et al. Large variations in the thermosphere and ionosphere during minor geomagnetic disturbances in April 2002 and their association with IMF $B_{\mathrm{y}}$. J. Geophys. Res. 2006, vol. 111, A03303. DOI: 10.1029/2004JA010683.

Kushnarenko G.P., Kuznetsova G.M., Yakovleva O.E. Geomagnetic storm effects at F1 layer altitudes in various periods of solar activity (Irkutsk station). Geomagnetism and Aeronomy. 2018, vol. 58, no. 2, pp. 201-206. DOI: $10.1134 /$ S0016793218020135.

Lastovicka J. Monitoring and forecasting of ionospheric space weather effects of geomagnetic storms. J. Atmos. SolarTerr. Phys. 2002, vol. 64, pp. 697-705. DOI: 10.1016/S13646826(02)00031-7.

Lastovicka J. On the role of solar and geomagnetic activity in long-term trends in the atmosphere-ionosphere system. $J$. Atmos Solar-Terr. Phys. 2005, vol. 67, pp. 83-92. DOI: 10.1016/j.jastp.2004.07.019.

Panasyuk M.I., Kuznetsov S.N., Lazutin L.L., Alexeev I.I., Antonova A.E., Belenkaya E.S., Bobrovnikov S.Yu., Veselovsky I.S., et al. Magnetic storms in October 2003. Cosmic Res. 2004, vol. 42, no. 5, pp. 489-534. DOI: 10.1023/B:COSM. 0000046230.62353 .61 .

Physics of the Upper Atmosphere. Ratcliffe J.A. (ed.) London, Academic Press, 1960, 597 p.

Picone J.M., Hedin A.E., Drob D.P., Aikin A.C. (GTD72000) NRLMSISE-00 Empirical model of the atmosphere: statistical comparisons and scientific issues. J. Geophys. Res. 2002, vol. 107, no. A12, pp. 1469. DOI: 10.1029/2002JA009430.

Polekh N.M., Chernigovskaya M.A., Yakovleva O.E. On the formation of the F1 layer during sudden stratospheric warming. Solar-Terr. Phys. 2019, vol. 5, no. 3, pp. 117-127. DOI: $10.12737 /$ stp-53201914.

Polyakov V.M., Shchepkin L.A., Kazimirovsky E.S., Kokourov V.D. Ionosfernye protsessy [Ionospheric processes]. Novosibirsk, Nauka Publ., 1968, 536 p. (In Russian).

Ratovsky K.G., Klimenko M.V., Klimenko V.V., Chirik N.V., Korenkova N.A., Kotova D.C. Geomagnetic storm aftereffects: statistical analysis and theoretical explanation. Solar-Terr. Phys. 2018, vol. 4, no. 4, pp. 26-32. DOI: $10.12737 /$ stp-44201804.

Shchepkin L.A., Klimov N.N. Termosfera Zemli [The Earth thermosphere]. Moscow, Nauka Publ., 1980, 220 p. (In Russian).

Shchepkin L.A., Kushnarenko G.P., Freizon I.A., Kuznetsova G.M. The electron density connection with the thermospheric state in the middle ionosphere. Geomagnetizm $i$ aeronomiya [Geomagnetism and Aeronomy]. 1997, vol. 37, no. 5, pp. 106-113. (In Russian).

Shchepkin L.A., Kushnarenko G.P., Kuznetsova G.M. Annual electron density variations in F1 region of ionosphere. Solnechno-zemnaya fizika [Solar-Terr. Phys]. 2005, vol. 7, pp. 62-65. (In Russian).

Shchepkin L.A., Kuznetsova G.M., Kushnarenko G.P., Ratovsky K.G. The interpretation of electron density measurements with using semi-empirical model. Solnechnozemnaya fizika [Solar-Terr. Phys]. 2007, vol. 10, pp. 89-92. (In Russian).

Shchepkin L.A., Kuznetsova G.M., Kushnarenko G.P., Ratovsky K.G. Approximation of electron density measurements data in middle ionosphere during the low solar activity. Solnechno-zemnaya fizika [Solar-Terr. Phys]. 2008, vol. 11, pp. 66-69. (In Russian).

Shchepkin L.A., Kushnarenko G.P., Kuznetsova G.M. Model description of electron concentration in the middle ionosphere. Solnechno-zemnaya fizika [Solar-Terr. Phys]. 2009, vol. 13, pp. 14-18. (In Russian). 
Tobiska W.K., Eparvier F.G. EUV97: Improvements to EUV irradiance modeling in the soft X-rays and EUV. Solar Phys. 1998, vol. 147, no. 1, pp. 147-159. DOI: 10.1023/A:1004931416167.

Whitten R., Poppoff I. Osnovy aeronomii [Fundamentals of Aeronomy]. Leningrad, Gydrometeoizdat Publ., 1977, 408 p. (In Russian). English edition: Whitten R.C., Poppoff I.G. Fundamentals of Aeronomy. New York, John Wiley \& Sons, Inc., 1971, $462 \mathrm{p}$.

Yasyukevich Y., Yasyukevich A., Ratovsky K., Klimenko M., Klimenko V., Chirik N. Winter anomaly in $N_{\mathrm{m}} \mathrm{F} 2$ and TEC: when and where it can occur. J. Space Weather
Space Clim. 2018, vol. 8, no. A45. DOI: $10.1051 / \mathrm{swsc} / 2018036$.

URL: http//ckp-rf.ru/ckp/3056 (accessed 31 March 2021). URL: http//wdc.kugi.kyoto-u.ac.jp (accessed 31 March 2021).

How to cite this article

Kushnarenko G.P., Yakovleva O.E., Kuznetsova G.M. Signs of anomalous behavior of the ionosphere in 2003-2014 at F1-layer heights over Irkutsk. Solar-Terrestrial Physics. 2021. Vol. 7. Iss. 2. P. 74-80. DOI: 10.12737/stp-72202108. 